\title{
Fractured Miniscrew Retrieval through Flapless Vibration Technique: A Mini Review and Case Report
}

\author{
${ }^{1}$ Sunil K Rath, ${ }^{2}$ Choudhury S Swain, ${ }^{3}$ Subhashree M Panda
}

\begin{abstract}
Nowadays, miniscrew anchorage system is encouraged to obtain better results in orthodontic treatment. This system also brings emergency complications like fractures during insertion of these miniscrews. According to protocol flap-raising technique, a periodontist should be consulted during retrieval of the fractured miniscrew. Here, we propose a new technique that can retrieve the fractured implant with uneventful healing by the vibration of micromotor blunt burs or ultrasonic scaler tips with reinsertion in 7 days.
\end{abstract}

Keywords: Flapless vibration technique, Microimplant fracture, Retrieval of implant.

How to cite this article: Rath SK, Swain CS, Panda SM. Fractured Miniscrew Retrieval through Flapless Vibration Technique: A Mini Review and Case Report. Int J Oral Implantol Clin Res 2017;8(1):31-33.

\section{Source of support: Nil}

Conflict of interest: None

\section{INTRODUCTION}

Anchorage has a very critical position in orthodontic treatment planning. Conventional methods of anchorage planning may lead to unwanted tooth movements, may rely on patient compliance, and can have a limitation in patients with compromised dentition. Temporary anchorage devices (TADs) are considered to be absolute stationary in clinical point. These can increase the horizon of orthodontic tooth movement with a little increase in investment. The biggest advantage which can be considered is a clinically acceptable result with avoidance of orthognathic surgery. Going through history, some landmark events have been documented:

- Skeletal anchorage in orthodontics: In the 1980s, Creekmore and Eklund ${ }^{1}$ used a titanium screw to intrude upper anterior tooth in an orthognathic patient.

\footnotetext{
${ }^{1}$ Senior Resident, ${ }^{2,3}$ Postgraduate Student

1,2Department of Orthodontics, Srirama Chandra Bhanja Dental College \& Hospital, Cuttack, Odisha, India

${ }^{3}$ Department of Periodontics, Srirama Chandra Bhanja Dental College \& Hospital, Cuttack, Odisha, India

Corresponding Author: Sunil K Rath, Senior Resident Department of Orthodontics, Srirama Chandra Bhanja Dental College \& Hospital, Cuttack, Odisha, India, Phone: +917376904509 e-mail: vikybds@gmail.com
}

- Retraction of canines: Robert et $\mathrm{al}^{2}$ used endosseous mini implants to protract molars to the edentulous space.

- The development of miniplates and miniscrews occurred in East Asia and the whole world recognized the results.

- The term "TAD" was introduced in 2005 by Mah and Bergstrand. ${ }^{3}$

In this article, the terms implant, miniscrew, and TAD are used interchangeably. Miniscrews have insertion torque ranging from 3 to $10 \mathrm{Ncm}$, much smaller than the breaking torque disclosed by the manufacturer. ${ }^{4,5}$ Probably this is the reason why miniscrews fracture. Here we present a case of screw fracture and retrieval in the chair side, through a simplified procedure.

\section{CASE REPORT}

A 26-year-old female patient reported to our orthodontic clinic with chief complaint of protruded front teeth. On examination, we found missing 36, 45, 46 and planned for extraction of two upper first premolar tooth and closure of all the spaces left out of the lower molar spaces for prosthodontic rehabilitation. For anchorage, the plan was to have four miniscrews (two in upper between second premolar and first molar, two in lower in edentulous area). After alignment and leveling, miniscrews in upper region were placed and same in edentulous 36 area. The inadvertent accident occurred during placing the TAD in 46 region (Fig. 1). When trying to insert the implant $1.5 \times$ $9 \mathrm{~mm}$, it fractured after insertion of $5 \mathrm{~mm}$.

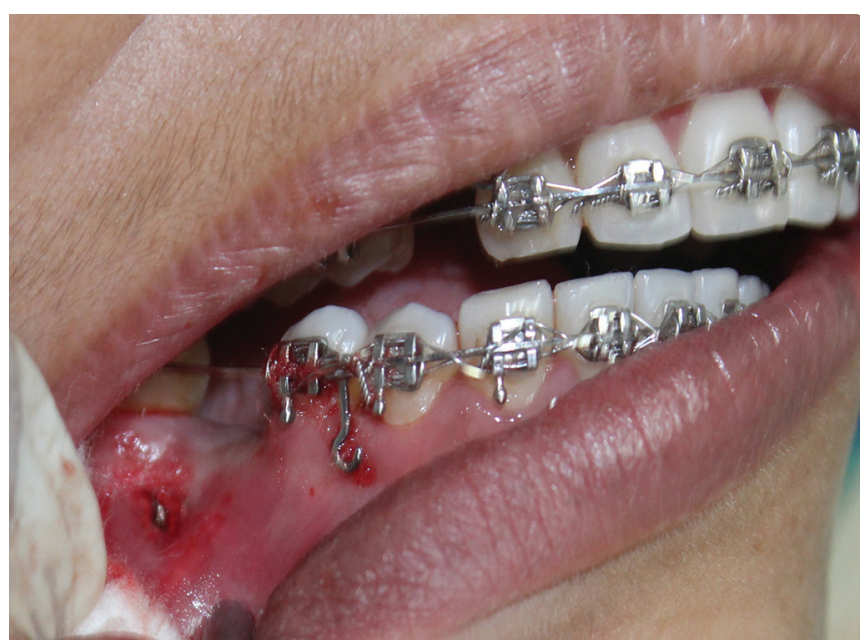

Fig. 1: Fractured TAD in 46 region 


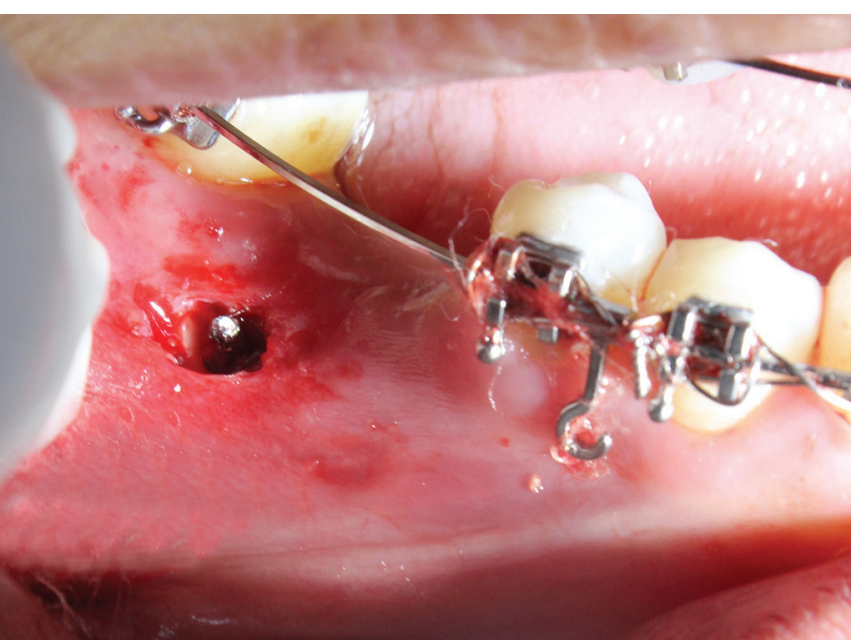

Fig. 2: Circular groove in TAD periphery

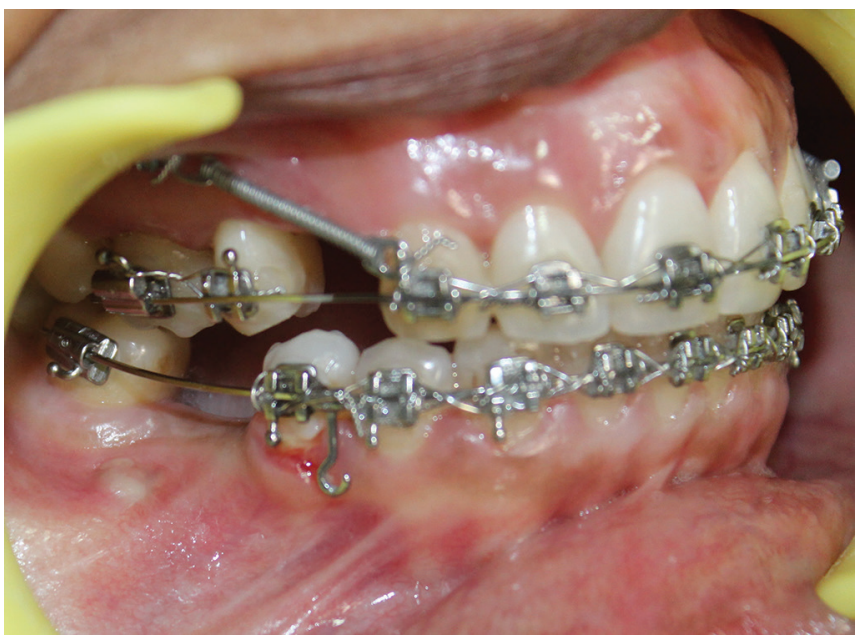

Fig. 4: Healing after 4 days

\section{RETRIEVAL}

The cardinal rule for retrieval is to raise the flap, remove the miniscrew through reverse torque. But the patient did not agree for the surgery. So the treatment plan was changed for removal of TAD without flap raising.

A contra-angled micromotor handpiece with low speed was used with profuse irrigation and a circular groove of 0.5 $\mathrm{mm}$ width was made in the implant periphery (Fig. 2). With a low speed, we just touched the microimplant to induce some vibration so that the microimplant got loosened. Then the screw was held with Weingart plier and reverse torque was given. The broken screw came out with minimal injury (Fig. 3). Then a gauze pack with zinc oxide eugenol paste was placed in that region as periodontal pack.

After 4 days, the pack was removed and left open for next 3 days, with topical chlorohexidine gel application (Fig. 4). On the 7th day, the same site was prepared for miniscrew insertion. The second miniscrew was firm immediately after placement, but force application was scheduled for next few days (Fig. 5).

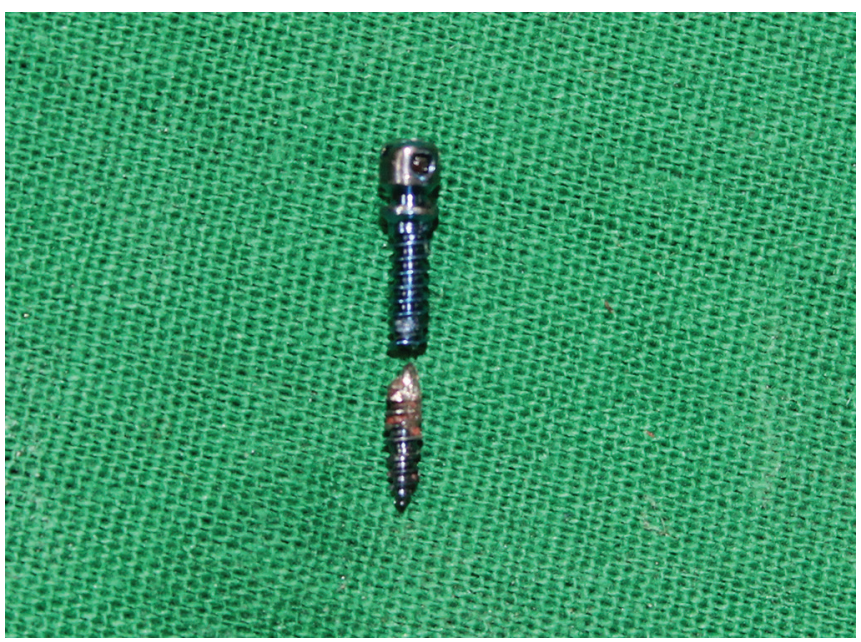

Fig. 3: Retrieved fractured TAD in toto

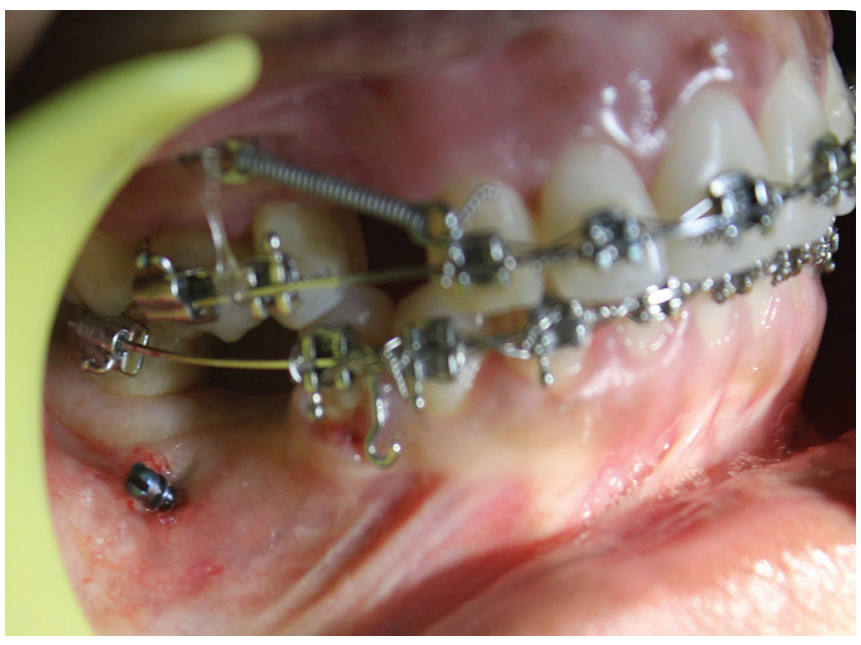

Fig. 5: Reinsertion after 7 days

\section{DISCUSSION}

Factors responsible for miniscrew fracture:

- Insertion torque

- Bone quality

- Pilot hole size

- Thread design

- Insertion methodology

- Osseointegration, etc.

In a study, it was concluded that insertion torque is directly proportional to fracture potential of implants. ${ }^{6}$ Incidence of miniscrew fracture ranges from 4 to $9 \% .{ }^{78}$ The precautions one has to take before implant placement are (1) bone density measurement using cone beam computed tomography, (2) pilot drills should be used before insertion if resistance occurred (felt), (3) torque measurement during insertion. Optimal range of torque is 5 to $10 \mathrm{Ncm}$, values exceeding $10 \mathrm{Ncm}$ may result in fracture of TAD. ${ }^{4}$

If fracture occurred, then the length of miniscrew inside the bone is to be assessed clinically through accurate measurement of the remaining part. Decision should 
be taken whether that should be removed or left inside. Then a periodontal consultation is required whether to raise the flap. Circumferential bone removal seems to be a better method for removal, but that should be judiciously removed.

Advantage of our method is that the procedure requires minimal technical skill with less chair side time in doing the retrieval procedure and nearly optimum healing at the surgical site. The limitation could be soft tissue injury, but, i.e., so minimal that it heals uneventfully within 7 days. The loosening of the fractured segment through bur or ultrasonic scaler tip with low frequency has a great advantage over direct reverse torque.

\section{CONCLUSION}

The flapless vibration method can be used in retrieval of fractured TADs if the length of fractured segment is minimal; in our case, it is $4 \mathrm{~mm}$ only. The vibration through blunt end burs of micromotor or ultrasonic scaler is an important step. But, careful evaluation of the clinical condition and patient's consent should be taken into consideration before planning for any surgical procedure. Further clinical studies are required for application of this protocol in fractured miniscrew removal.

\section{REFERENCES}

1. Creekmore TD, Eklund MK. The possibility of skeletal anchorage. J Clin Orthod 1983 Apr;17(4):266-269.

2. Roberts WE, Marshall KJ, Mozsary PG. Rigid endosseous implant utilized as anchorage to protract molars and close an atrophic extraction site. Angle Orthod 1990 Summer;60(2): 135-152.

3. Mah J, Bergstrand F. Temporary anchorage devices: a status report. J Clin Orthod 2005 Mar;39(3):132-136.

4. Motoyoshi M, Hirabayashi M, Uemura M, Shimizu N. Recommended placement torque when tightening an orthodontic mini-implant. Clin Oral Implants Res 2006 Feb;17(1): 109-114.

5. Meursinge Reynders RA, Ronchi L, Ladu L, van Etten-Jamaludin F, Bipat S. Insertion torque and success of orthodontic miniimplants: a systematic review. Am J Orthod Dentofacial Orthop 2012 Nov;142(5):596-614.

6. Suzuki EY, Suzuki B. Placement and removal torque values of orthodontic miniscrew implants. Am J Orthod Dentofacial Orthop 2011 May;139(5):669-678.

7. Barros SE, Janson G, Chiqueto K, Garib DG, Janson M. Effect of mini-implant diameter on fracture risk and self-drilling efficacy. Am J Orthod Dentofacial Orthop 2011 Oct;140(4): e181-e192.

8. Büchter A, Wiechmann D, Koerdt S, Wiesmann HP, Piffko J, Meyer U. Load-related implant reaction of mini-implants used for orthodontic anchorage. Clin Oral Implants Res 2005 Aug;16(4):473-479. 